\title{
Amelioration of mechanical and rheological characteristics of a ceramic Slip by adding of bentonite
}

\author{
Hammadi L *, Boudouaia W, Belaid Y \\ Laboratoire de Rhéologie, Transport et Traitement des Fluides Complexes (LRTTFC), Faculté d'Architecture et \\ de Génie civil, Département d'Hydraulique, Université des Sciences et de la Technologie d'Oran (USTO MB) B.P. \\ 1505 Oran-EL-M'naouar 31000, Algérie \\ * Corresponding Author: larbi.hammadi@univ-usto.dz or hammadi7280@yahoo.fr \\ Received: 29-01-2018 \\ Revised: 16-02-2018 \\ Accepted: 20-02-2018

\begin{abstract}
This work is a contribution to the amelioration of the mechanical and rheological properties of a slip of ceramic used in the ceramic fabrication process. A study of characterization of slip of ceramic modified by bentonite has been accomplished chemically, physically, mechanically and rheologically. Chemical analysis showed that the slip modified by bentonite consist essentially of silica with a ratio $\left(\mathrm{SiO}_{2} / \mathrm{Al}_{2} \mathrm{O}_{3}\right)$ average equal to 3.5 and the ratio of clays $\left(\mathrm{Al}_{2} \mathrm{O}_{3} / \mathrm{SiO}_{2}\right)$ is relatively stable with increasing percentage of bentonite in the slip, with an average 0.28 . The mechanical and rheological tests showing that increasing the percentage of bentonite in base slip caused an increase in the mechanical resistance, the yield stress and rapid decrease in density of the slip.
\end{abstract}

Key words: Amelioration, ceramic slip, yields stress, mechanical and rheological, density.

\section{Introduction}

The ceramic tile industry today is an important sector whose technological innovation and market trends have drawn a complex picture of products and processes. According to Dondi et al. (2014) the production of ceramic tiles is growing worldwide at a rate of 300 million $\mathrm{m}^{2} /$ year and has already passed 10 billion $\mathrm{m}^{2}$ in 2012. For this reason a many additives have been added to slip of ceramic such as the electrolytes (Hayashi, 2012), polymers (Mansur, 2008), Sludge of wastewater treatment (Martínez-García, 2012) in order to improve the quality of ceramic. The objective of this study is to ameliorate the mechanical and rheological properties of slip of ceramic by bentonite clay. It is noted that the bentonite is a natural clay whose mechanical properties (viscosity, fluidification, flow threshold, thixotropy) are widely used in the products of our daily life. Its field of application extends from civil engineering (Tan, 2014; Besq, 2003), drilling fluid (hammadi, 2014; Coussot, 2006), pharmacy and food application. The bentonite is also employed as a thickener in waterproofing of hydraulic structures (dams, large reservoirs, etc...).

\section{Materials and methods}

\subsection{Materials and samples preparation}

The raw materials used in this study is from the "CERAL" Company of Hassi -Amer - Oran. This company uses clays at fixed percentages by adding deflocculants to facilitate mold release from the plaster molds. Table 1 presents the various materials used by the company CERAL for the manufacture of ceramics.

Table 1. The materials used by the company CERAL for the manufacture of ceramics.

\begin{tabular}{|c|c|}
\hline Materials & Percentage (\%) \\
\hline \hline Schist 1 & 61 \\
\hline Schist 2 & 10 \\
\hline Sandstone & 17 \\
\hline Clay & 12 \\
\hline
\end{tabular}


In order to improve the physicochemical and mechanical characteristics of the slip of ceramic used by the company CERAL we tried to replace the clay used by bentonite of Maghnia without modifying the percentage of the other comps (Schist 1, Schist 2 and Sandstone). The table 2 shows the percentage of mixtures.

Table 2. The percentage of mixtures used in this study.

\begin{tabular}{|c|c|c|c|c|}
\hline Materials & \multicolumn{4}{|c|}{ Percentage (\%) } \\
\hline \hline Bentonite & 0 & 3 & 6 & 9 \\
\hline Schist 1 & 61 & 61 & 61 & 61 \\
\hline Schist 2 & 10 & 10 & 10 & 10 \\
\hline Sandstone & 17 & 17 & 17 & 17 \\
\hline Clay & 12 & 9 & 6 & 3 \\
\hline
\end{tabular}

\subsection{Experimental set up}

\subsubsection{Mechanical characterizations}

The Mechanical characterizations of the slip of ceramic and slip of ceramic with bentonite were carried out using the press (ceramic Instruments Srl) SASSUOLO-ITALY, the maximum pressure of this apparatus is 250 bar and a bending apparatus FLEXI 1000 LX GABTEC, to the company CERAMIR from HASSI AMER Oran. Samples of $100 \mathrm{~g}$ were introduced into the press apparatus and a pressure of 80 bars was applied to make tiles with a thickness of $7.8 \mathrm{~mm}$, a width of 100 $\mathrm{mm}$ and a width of $45 \mathrm{~mm}$. Then, tiles were introduced in a drying oven at $110^{\circ} \mathrm{C}$ for 2 hours. After completion of the tiles and drying, flexural tests were carried out. After 2 hours of drying at $110^{\circ} \mathrm{C}$, the tiles of ceramic are placed in the oven at a temperature of $1140^{\circ} \mathrm{C}$ for $45 \mathrm{~min}$ to carry out the sintering tests. Figure 1 shows the state of the tiles of ceramic after drying at $110^{\circ} \mathrm{C}$.

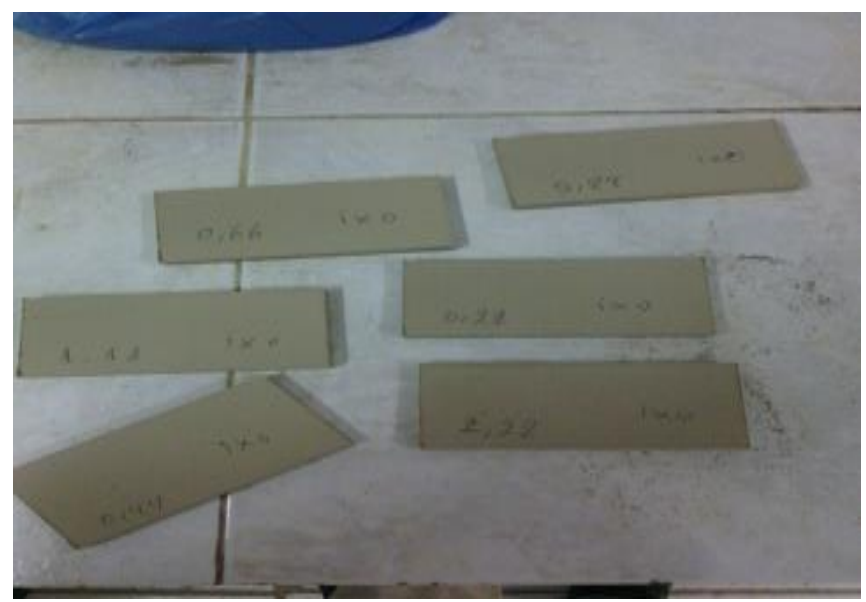

Fig 1 . The state of the tiles of ceramic after drying at $110^{\circ} \mathrm{C}$.

\subsubsection{Rheological measurements}

The rheological measurements were performed by using a torque controlled rheometer (RS600 from Thermo-Fischer) connected to a temperature controlled water bath and equipped with a plate-cone geometry (diameter: $60 \mathrm{~mm}$; angle: 2 degree; gap: $105 \mu \mathrm{m}$ ). A solvent trap was placed around the measuring device in order to minimize solvent evaporation. After the bending tests, the samples are recovered, ground and then passed through the $100 \mu \mathrm{m}$ sieves in order to make granulometric tar compatible with the cone/plane geometry used for the rheological measurements. The slip in powder form is then dispersed with magnetic stirring for 3 hours in distilled water at a concentration of $58 \%$ by weight. The suspension obtained is left to stand for 24 hours. The creep and recovery tests after a rest time of $600 \mathrm{~s}$, creep and recovery tests were performed by first applying a constant shear stress of 10 Pa during $180 \mathrm{~s}$ to the samples of slip 
and then removing the shear stress during $180 \mathrm{~s}$ in order to obtain the time dependence of the compliance J.

\section{Results and discussion}

\subsection{Chemical analysis}

Chemical analysis of the samples was carried out at the laboratory of the LAFARGE Company. The results are summarized in Table 3.

Table 3. Chemical analysis of slip modified by bentonite.

\begin{tabular}{|c|c|c|c|c|}
\hline Elements (\%) & 0\% of Bentonite & 3\% of Bentonite & 6\% of Bentonite & 9\% of Bentonite \\
\hline \hline $\mathrm{SiO}_{2}$ & 59.83 & 16.97 & 7.69 & 3.10 \\
\hline $\mathrm{Al}_{2} \mathrm{O}_{3}$ & 60.68 & 17.36 & 7.62 & 2.49 \\
\hline $\mathrm{Fe}_{2} \mathrm{O}_{3}$ & 60.93 & 16.26 & 7.37 & 2.27 \\
\hline $\mathrm{CaO}$ & 58.10 & 17.52 & 7.14 & 2.15 \\
\hline
\end{tabular}

Table 3 shows that the slip of ceramic modified by bentonite consists essentially of silica with average ratio of $\mathrm{SiO}_{2} / \mathrm{Al}_{2} \mathrm{O}_{3}$ equal to 3.5. According to Robert and Tessier (1974), the values of the ratio $\mathrm{SiO}_{2} / \mathrm{Al}_{2} \mathrm{O}_{3}$ are generally between 2 and 4 in clays, because of numerous substitutions. It is also observed that the clay ratio $\left(\mathrm{Al}_{2} \mathrm{O}_{3} / \mathrm{SiO}_{2}\right)$ is relatively stable with the increase of bentonite content in the slip of ceramic, with an average of 0.28 . The iron oxide content is quite high in the slip of ceramic modified by bentonite. It is also observed that the increase the quaintly of bentonite in slip of ceramic causes a decrease of $\mathrm{CaO}$.

\subsection{Amelioration of the mechanical characteristics of ceramic slip by bentonite}

\subsubsection{Effect of bentonite on density of ceramic slip}

Figure 2 shows evolution of the density of slip as a function of bentonite concentration added to slip. It can be observed that the density is decreased with the increase of the percentage of bentonite in slip of ceramic. This decrease can be explained by the increase in the volume of the slurry suspensions caused by the swelling of the bentonite.

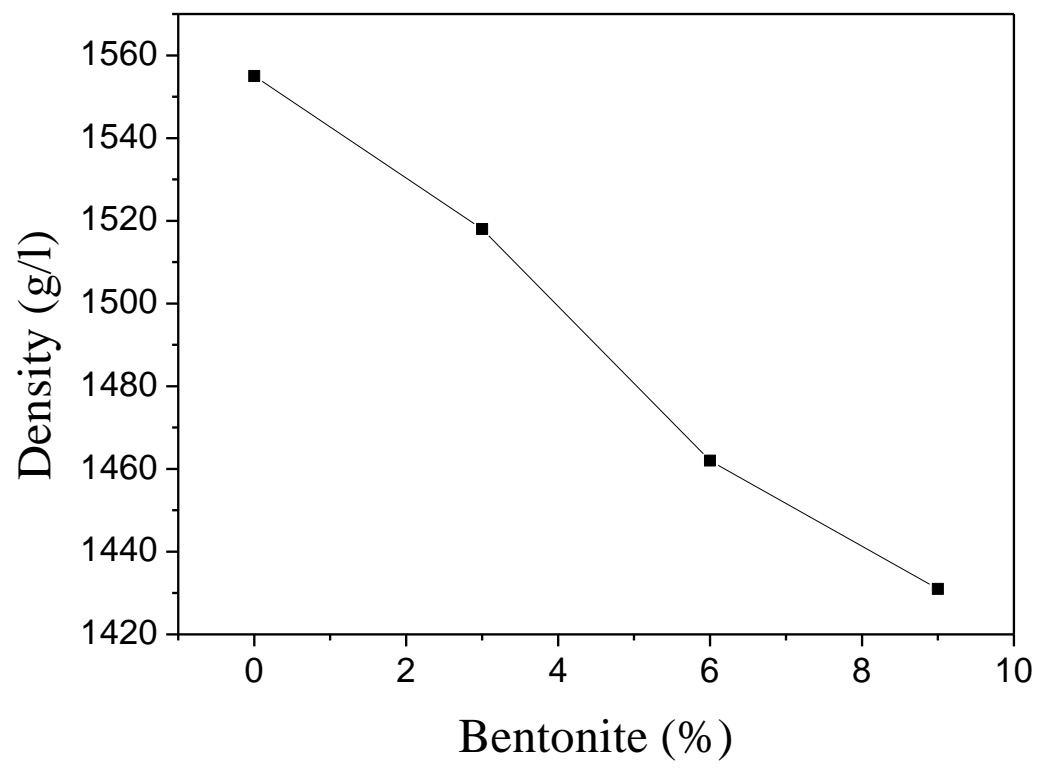

Fig 2. Evolution of the density of slip as a function of bentonite concentration added to slip of ceramic. 


\subsubsection{Effect of bentonite on Mechanical resistance of slip}

The Figure 3 shows the variation of mechanical resistance of slip as a function of the concentration of bentonite added to ceramic slip. We is It can be observed in the figure 3 , an increase in the mechanical tensile bending strength with the increase in the amount of bentonite in the ceramic slip, this increase being of tensile bending strength can be explained by the increase in the silica content $\left(\mathrm{SiO}_{2}\right)$.

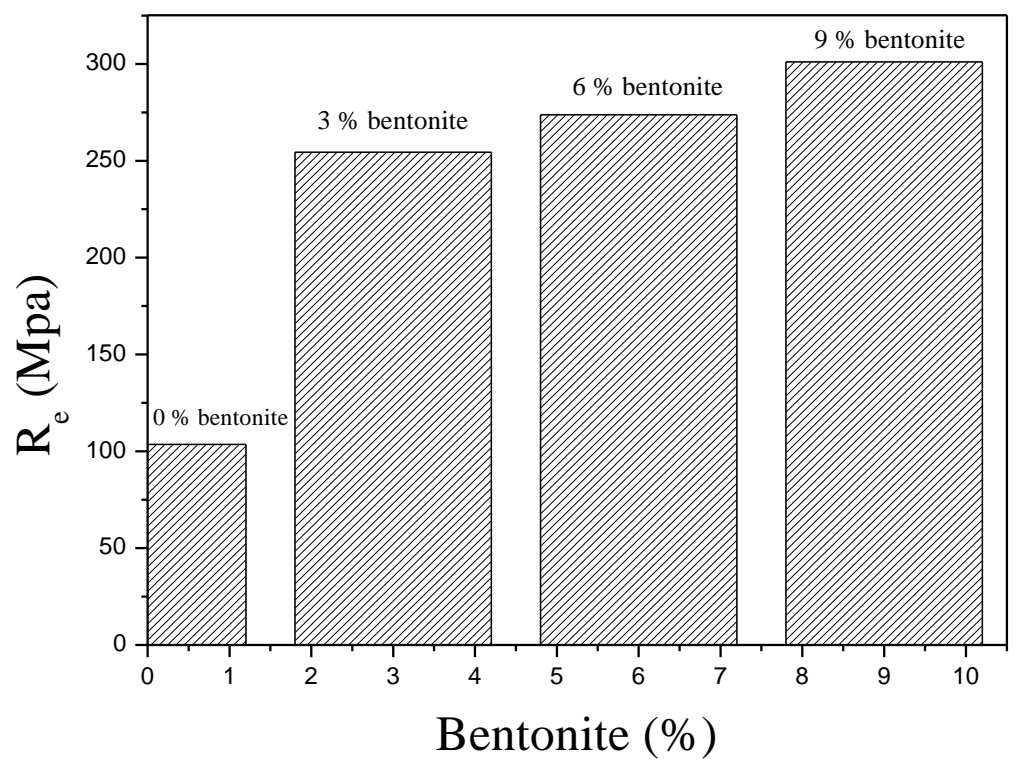

Fig 3. Tensile bending strength as a function of bentonite concentration added to ceramic slip after baking at $110{ }^{\circ} \mathrm{C}$.

\subsection{Improvement of the rheological characteristics of the slip of ceramic by bentonite}

Figure 4 shows the shear stress evolution as a function of shear rate for different concentration $(0 \%, 3 \%, 6 \%$, and $9 \%)$ of bentonite added in slip of ceramic.

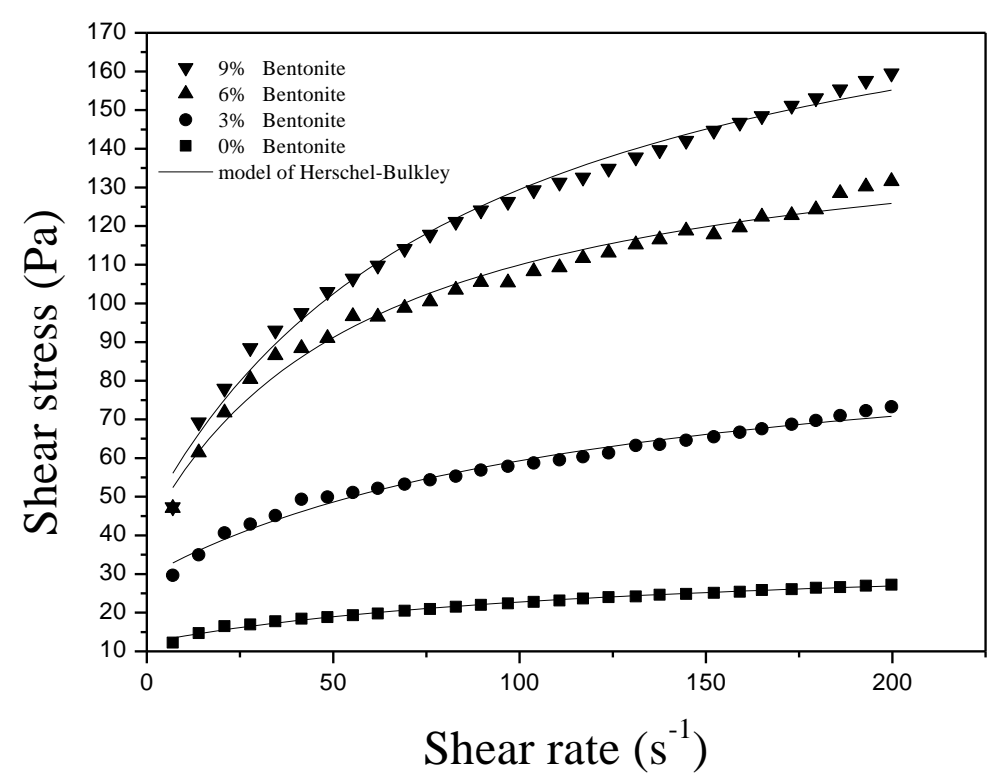

Fig. 4. shear stress $\tau$ as a function of the shear rate $\dot{\gamma}$ at different concentration of bentonite added in slip of ceramic. The solid lines correspond to the curve fitting to model of Herschel-Bulkley. 
From figure 4, it can be observed an increase of the shear stress of the modified slip is occurred with the increase of the concentration of bentonite added to the slip of ceramic. The variation of the shear stress $\tau$ as a function of the shear rate $\dot{\gamma}$ at different concentration of bentonite added in slip of ceramic clearly shows a non-Newtonian behavior after a yield stress. Therefore experimental data were fitted to the classical model of Herschel-Bulkley with the coefficients of regression equal to 0.99 for all quantity of bentonite added in slip of ceramic:

$\tau=\tau_{0}+K \dot{\gamma}^{n}$

Where $\tau_{0}$ is the yield stress in $\mathrm{Pa}, \mathrm{K}$ the consistency index in Pa.s ${ }^{\mathrm{n}}$ and $\mathrm{n}$ is the flow index.

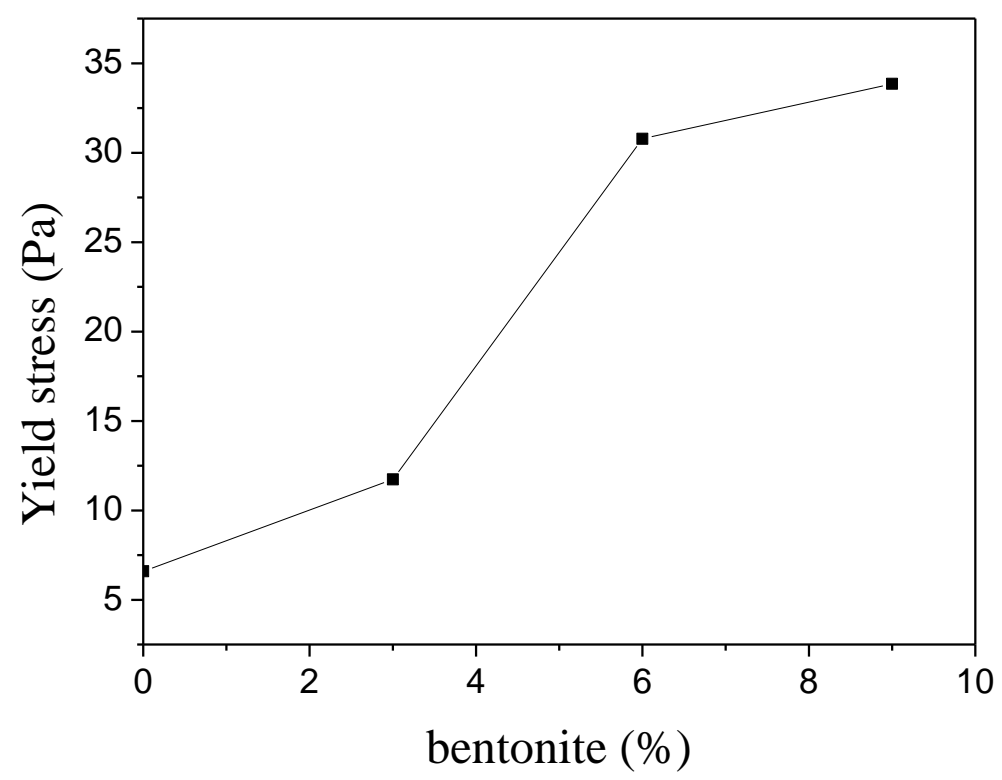

Fig 5. Yield stress as a function of bentonite added in silp of ceramic.

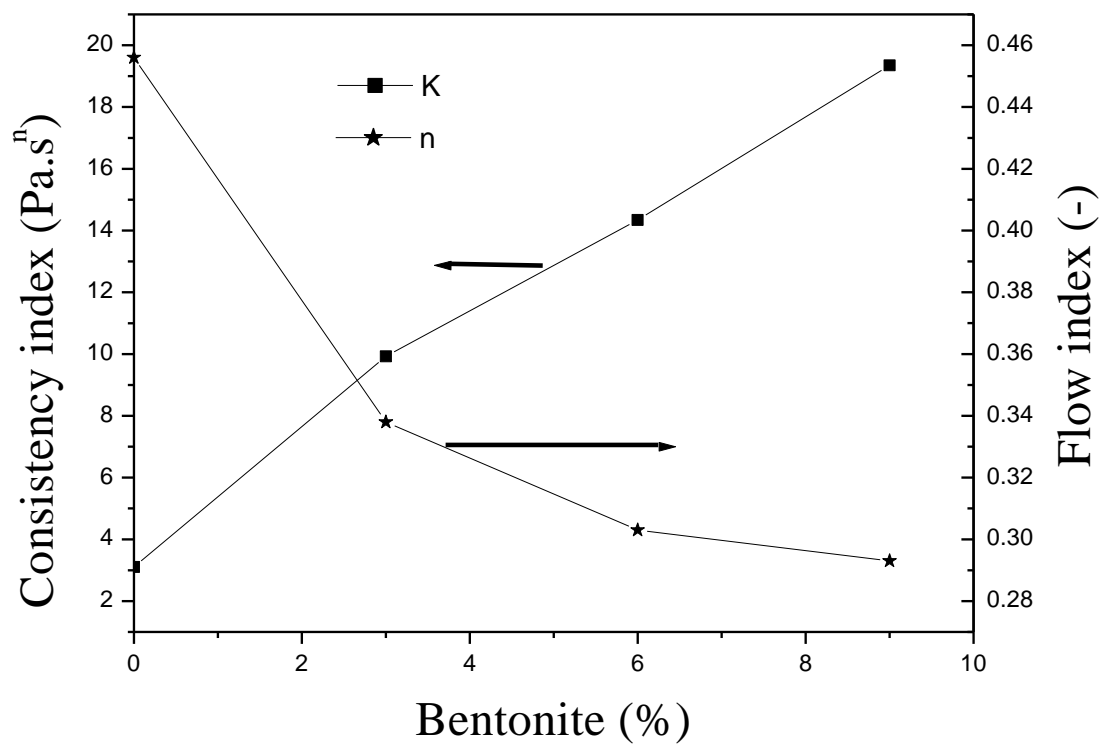

Fig.6. Consistency index and flow index as a function of bentonite added in silp of ceramic.

The fitted parameters of the model of Herschel-Bukley as a function of mass concentration of bentonite added to slip of ceramic are presented in Figs 5 and 6. It appears that yield stress and consistency index increase with increasing mass concentration of bentonite added to slip of 
ceramic. Concerning the flow index, it decreases with increasing mass concentration of bentonite in slip of ceramic. This increase on the yield stress, consistency index and the decrease of flow index can be explained by the increased interactions between the clay and bentonite particles. In addition to a hydrodynamic contribution, the bentonite particles thus provide an additional contribution in the form of a network of interactions, which modifies the mechanical and rheological behavior of the slip of ceramic.

\subsection{Effect of bentonite on creep and recovery of slip of ceramic}

Figure 7 shows the values of compliance: $J(t)=\frac{\gamma}{\tau}$, as a function of time, for the creep tests corresponding to the ceramic slip studied for mass concentration of bentonite range between 0 and $9 \%$ added in ceramic slip, in a time interval between 0 and 180 s. For the interval time $180 s \leq 360 s$, we have represented the corresponding recovery. We observe on this figure a decrease of the elastic compliance with the increase of quantity of bentonite added to slip of ceramic. i.e., increase of the elastic modulus: $\frac{1}{J}$, indicating an increase of the viscoelastic properties of modified slip. In other words, the creep deformation decreases with increasing the bentonite in slip and the time necessary to reach a constant deformation during recovery, after removal of the shear stress, decreases. This behavior could be explained by the interaction between the granules of the clays suspension.

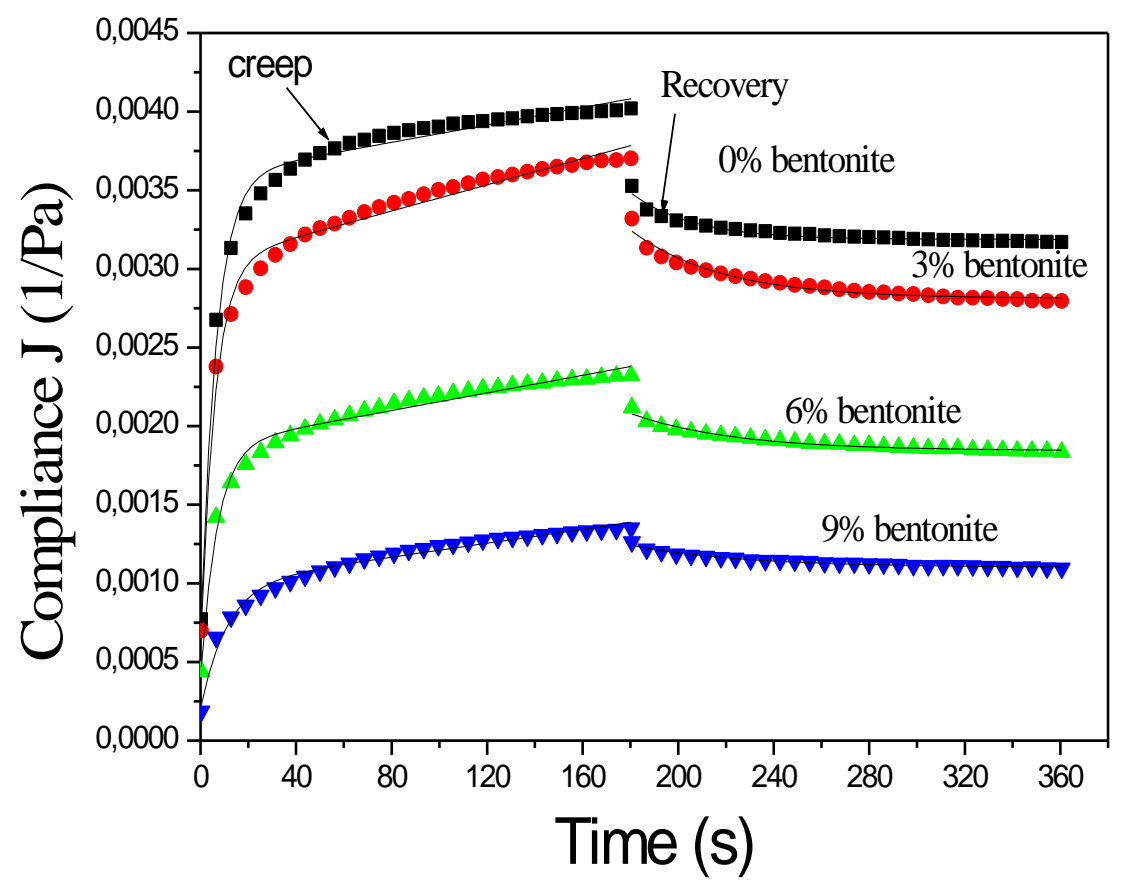

Fig.7. Compliance versus time in creep and recovery test for different content of bentonite added to ceramic slip. The solid lines correspond to the curve fitting to Generalized Kelvin-Voigt model.

The elastic properties were defined by correlating the results with the well-known viscoelastic models of Burger model or Generalized Kelvin-Voigt model (Hammadi and Ponton, 2017), comprising the association in series of the Maxwell and the Kelvin-Voigt models.

The creep curves are described by:

$J_{F}=J_{0}+\frac{t}{\eta_{0}}+\sum_{i=1}^{N} J_{i}\left[1-\exp \left(-\frac{t}{\theta_{i}}\right)\right]$

$\theta_{i}=\frac{J_{i}}{\eta_{i}}$

Whereas the recovery strain is given by: 
$J_{R}=\frac{t_{1}}{\eta_{0}}+\sum_{i=1}^{N} J_{i}\left[\exp \left(\frac{t_{1}}{\theta_{i}}\right)-1\right] \exp \left(-\frac{t}{\theta_{i}}\right)$

Where $J_{0}$ is the purely elastic contribution (or the instantaneous elastic compliance), $\eta_{0}$ is the purely viscous contribution, represented by the dashpot of the Maxwell model, i.e., the uncoupled or residual steady-state viscosity obtained from the creep curve at long times when the compliance curve is linear, $J_{i}$ is the contribution to retarded elastic compliance, $\theta_{i}$ is the retarded time, $\eta_{i}$ is the retarded viscosity and $t_{1}$ is the time where the stress is applied for $t \leq t_{1}$ and removed at $t=t_{1}$.

The fittings in Fig. 7 were performed with just one Kelvin-Voigt solid (N=1) and the fitting parameters are detailed in Table 3. The column $G_{0}=\frac{1}{J_{0}}$ represents the instantaneous elastic modulus of the Maxwell unit at $t=0$; that is, the instantaneous elastic response of the system and the column $G_{1}=\frac{1}{J_{1}}$ is the elastic modulus of Kelvin-Voigt. The latter represents the contributions of the retarded elastic region to the total compliance. The strong increase is observed in $G_{0}$ and $G_{1}$ when the quantity of bentonite added to slip of ceramic is changed between 0 and $9 \%$ is the manifestation of the shift from viscous to elastic behavior and an increase of the viscoelastic properties in that range of bentonite.

Table 3. Fitting parameters of the Creep-Recovery data in Fig. 7 , with $N=1$ in Eqs. (2) and (4).

\begin{tabular}{|c|c|c|c|c|c|c|}
\hline & \multicolumn{3}{|c|}{ Creep } & \multicolumn{3}{c|}{ Recovery } \\
\hline \hline Bentonite (\%) & $\mathrm{G}_{0}(\mathrm{~Pa})$ & $\mathrm{G}_{1}(\mathrm{~Pa})$ & $\eta_{0}$ (Pa.s) & $\mathrm{G}_{1}(\mathrm{~Pa})$ & $\eta_{0}$ (Pa.s) & $\theta_{1}(\mathrm{~s})$ \\
\hline 0 & 1470 & 345 & 161615 & 2272 & 56468 & 26 \\
\hline 3 & 1639 & 413 & 240173 & 3333 & 64016 & 38 \\
\hline 6 & 2439 & 680 & 357729 & 4166 & 97617 & 44 \\
\hline 9 & 4762 & 1266 & 454505 & 6666 & 163320 & 48 \\
\hline
\end{tabular}

Concerning $\eta_{0}$ let us mention that it has the meaning of viscosity of the system in the newtonian regime, whereas it shows a clearly increasing trend as the quantity of bentonite is increased in slip of ceramic. At high quantity of bentonite added to slip of ceramic, the applied stress of $10 \mathrm{~Pa}$ is not sufficient to break weak particle-to-particle bonds, and the suspensions do not flow. For lower quantity of bentonite added to slip of ceramic such resistance to flow is not so large, and this explains the values of $\eta_{0}$ and $G_{1}$ in this case the retarded deformation, related to the breaking and reconstruction of weak links between the particles. The characteristic relaxation time associated with these breaking/reconstruction processes is $\theta_{1}$.

\section{Conclusions}

Addition of bentonite clay on slip of ceramic greatly changed the mechanical and rheological properties of slip. The degree of interaction between bentonite and slip particles depended on the bentonite concentration added to the ceramic slip. The effect of bentonite on stationary nonNewtonian flow behavior of slip of ceramic was successfully modeled using the Herschel-Bulkley model over the studied range of bentonite added to slip of ceramic. The yield stress and the consistency index of ceramic slip modified are increased by increasing the quantity of bentonite in ceramic slip.

A strong increase of elastic modulus deduced from creep measurements fitted to generalized Kelvin-Voigt model with one element was observed when the quantity of benonite is increased between 0 and $9 \%$ added to slip of ceramic. The study has also shown an increase of mechanical resistance of ceramic slip with increase of quantity of bentonite added to ceramic slip.

\section{References}

Besq, A., Malfoy, C., Pantet, A., Monnet, P., \& Righi, D. (2003). Physicochemical characterisation and flow properties of some bentonite muds. Applied Clay Science, 23(5-6), 275-286. 
Coussot, P., Tabuteau, H., Chateau, X., Tocquer, L., \& Ovarlez, G. (2006). Aging and solid or liquid behavior in pastes. Journal of Rheology, 50(6), 975-994.

Dondi, M., Raimondo, M., \& Zanelli, C. (2014). Clays and bodies for ceramic tiles: Reappraisal and technological classification. Applied Clay Science, 96, 91-109.

Hammadi, L., Boudjenane, N., \& Belhadri, M. (2014). Effect of polyethylene oxide (PEO) and shear rate on rheological properties of bentonite clay. Applied Clay Science, 99, 306-311.

Hammadi, L., \& Ponton, A. (2017). Rheological Investigation of Vase of Dam: Effects of Aging Time, Shear Rate, and Temperature. Applied Rheology, 27(1).

Hayashi, A., Noi, K., Sakuda, A., \& Tatsumisago, M. (2012). Superionic glass-ceramic electrolytes for roomtemperature rechargeable sodium batteries. Nature communications, 3, 856 .

Mansur, A. A. P., Nascimento, O. L. D., Vasconcelos, W. L., \& Mansur, H. S. (2008). Chemical functionalization of ceramic tile surfaces by silane coupling agents: polymer modified mortar adhesion mechanism implications. Materials Research, 11(3), 293-302.

Martínez-García, C., Eliche-Quesada, D., Pérez-Villarejo, L., Iglesias-Godino, F. J., \& Corpas-Iglesias, F. A. (2012). Sludge valorization from wastewater treatment plant to its application on the ceramic industry. Journal of environmental management, 95, S343-S348.

Robert, M., \& Tessier, D. (1974). Méthode de préparation des argiles des sols pour des études minéralogiques. In Annales agronomiques, 25 :859-882.

Tan, O., Gungormus, G., \& Zaimoglu, A. S. (2014). Effect of Bentonite, Fly Ash and Silica Fume cement injections on uniaxial compressive strength of granular bases. KSCE Journal of Civil Engineering, 18(6), 1650-1654. 